
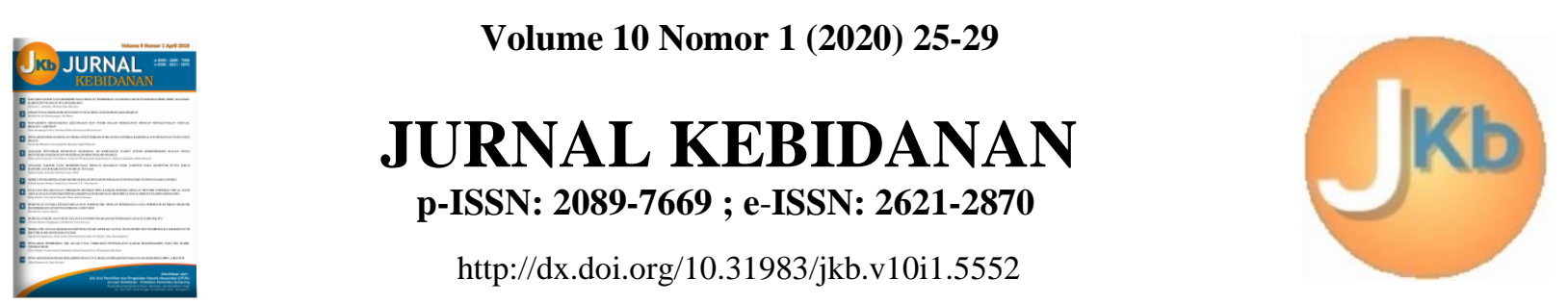

\title{
Effect of Carrot Juice To Decrease The Primary Dysmenorrhea Pain on Adolescent Girls in Dorm Poltekkes Kemenkes Pontianak
}

\author{
Dini Fitri Damayanti*, Sarah Aprilia, Emy Yulianti \\ Department of Midwifery, Poltekkes Kemenkes Pontianak \\ J1. Dr.Soedarso, Bangka Belitung Laut, Kecamatan Pontianak Tenggara, \\ Kota Pontianak, Kalimantan Barat, Indonesia \\ Corresponding author: Dini Fitri Damayanti \\ Email:dinifitrid@gmail.com
}

Received: January $28^{\text {th }}, 2020$; Revised: March $2^{\text {nd }}, 2020$; Accepted: April $13^{\text {th }}, 2020$

\begin{abstract}
Dysmenorrhea is pain during menstruation, usually with felt cramp and concentrated in the lower abdomen. Pain complaints from mild to severe. Based on the causes, dysmenorrhea was divided into two, namely primary and secondary dysmenorrhea. The method to treat dysmenorrhea was used painkillers, take a rest, take a deep breath, calm down, exercise lightly, eat vegetables and fruits, compress the pain parts with hot water. One of nonfarmacology method is use carrot juice. The purpose of this research is to find out carrot juice can reduce primary dysmenorrhea pain on adolescent girls in dorm Poltekkes Kemenkes Pontianak. This research was used the quasy experiment method with a pre and post test without control approach. The sampling technique was used purposive sampling. Data collections conduct from May to June 2019 used the NRS questionnaire, Sheet Procedure for Giving Carrot Juice. Data was analyzed by Wilcoxon test. The research results showed that before be given carrot juice, the middle value of primary dysmenorrhea pain was 6.00. After be given carrot juice, the middle value of primary dysmenorrhea pain was 2.00 , which means there is a difference in pain around 4.00 and a value of $p=0,000$ (p. 0.05). The conclusion is there are differences in the pain of primary dysmenorrhea before and after be given carrot juice.
\end{abstract}

Keywords: carrot juice; dysmenorrhea; adolescent girls

\section{Pendahuluan}

Masa remaja adalah periode waktu individu beralih dari fase anak ke fase dewasa pada usia antara 12 tahun sampai 24 tahun. Remaja mengalami perubahan dalam tiga aspek yaitu perkembangan kognitif, perkembangan fisik dan perkembangan psikososial. Perubahan-perubahan seperti tubuh badan semakin panjang dan tinggi, mulai berfungsinya alat-alat reproduksi serta tanda-tanda seksual yang tumbuh. [2] Masa pubertas pada wanita ditandai dengan datangnya menstruasi/haid, yang terjadi pada usia 10-16 tahun. Beberapa remaja mengalami gangguan pada saat haid yaitu mengalami nyeri pada saat haid (dismenorea).[8] Copyright @ 2020, JURNAL KEBIDANAN, http://ejournal.poltekkes-smg.ac.id/ojs/index.php/jurkeb/index
Dismenorea adalah nyeri saat haid, biasanya dengan rasa kram dan terpusat di abdomen bawah. Keluhan nyeri dapat bervariasi mulai dari ringan sampai berat. Gangguan sekunder menstruasi yang paling sering dikeluhkan adalah nyeri sebelum, saat atau sesudah menstruasi. Nyeri tersebut timbul akibat adanya hormon prostaglandin yang membuat otot uterus (rahim) berkontraksi.[6]

Berdasarkan penyebabnya dismenorea dibedakan menjadi dua, yaitu Dismenorea primer dan sekunder. Dismenorea primer biasanya terjadi mulai dari pertama haid/menarche usia 10-15 tahun sampai usia 25 tahun yang disebabkan oleh kontraksi uterus, dan tidak terdapat hubungan kelainan ginekologi. Sedangkan dismenorea sekunder disebabkan oleh kelainan yang terdapat 
dalam uterus dan saluran reproduksi. Remaja putri akan lebih sering merasakan sakit akibat dismenorea primer karena siklus hormonal yang dialami belum begitu stabil. Dismenorea primer ini akan sangat menganggu konsentrasi dan aktivitas para remaja putri.[1]

Angka kejadian dismenorea di Indonesia sebesar $64,25 \%$ yang terdiri dari $54,89 \%$ Dismenorea primer di antaranya nyeri saat menstruasi dan 9,36\% dismenorea sekunder di antaranya di sebabkan oleh infeksi yang lama pada saluran penghubung rahim (uterus).[9]

Cara mengatasi dismenorea dapat dilakukan dengan penjelasan dan nasihat, pemberian obat analgetik, terapi hormonal, terapi alternative.[11] Dismenorea juga dapat diobati dengan cara meminum obat pereda rasa sakit, beristirahat, menarik napas panjang, menenangkan diri, berolahraga ringan, mengkonsumsi sayur dan buah-buahan, mengompres bagian yang terasa sakit dengan air panas. Zat gizi yang dapat membantu meringankan dismenorea adalah kalsium, magnesium serta vitamin A, E, B6, dan C. Salah satu cara non obat-obatan yang digunakan adalah dengan menggunakan jus buah atau sayuran. Untuk meringankan nyeri haid dengan cara nonfarmakologi salah satunya adalah pemberian jus wortel dan jus alpukat.[5]

Wortel (Daucus Carota) merupakan salah satu sayuran yang paling banyak manfaatnya. Wortel mengandung gula, karotin, pektin, aspargin, serat, lemak, hidrat arang, kalsium, fosfor, besi, sodium, asam amino, minyak esensial, dan betakaroten. Wortel juga banyak mengandung vitamin A,B,C,D,E dan K.[7] Manfaat vitamin E dan betakaroten adalah bisa membantu pengeblokan formasi prostaglandin dan vitamin $\mathrm{E}$ juga bisa membantu mengatasi efek peningkatan produksi hormon prostaglandin. Hormon prostaglandin adalah hormon yang mempengaruhi terjadinya dismenorea. Prostaglandin yang berperan disini yaitu E2 (PGE2) dan F2a (PGF2a) [13]. Sedangkan manfaat beta karotin adalah dapat meminimalisir rasa nyeri analgetik.

Berdasarkan studi pendahuluan yang dilakukan pada tanggal 8 April 2019 didapatkan bahwa di Asrama Kebidanan Poltekkes Kemenkes Pontianak terdapat sebanyak 56 remaja putri. Dari wawancara yang dilakukan terdapat 3 orang yang mengalami nyeri ringan, 5 orang yang mengalami nyeri sedang, dan 2 orang mengalami nyeri berat. Sementara upaya untuk mengatasi dismenorea dengan cara non farmakologi belum pernah dilakukan oleh siswi yang mengalami dismenorea primer yaitu minum jus wortel.

Berdasarkan hal tersebut maka peneliti tertarik untuk meneliti pengaruh pemberian jus wortel terhadap nyeri dismenorea pada remaja putri di Asrama Kebidanan Poltekkes Kemenkes Pontianak.

\section{Metode Penelitian}

Desain yang digunakan adalah quasy experiment dengan pendekatan pre and post test without control. Populasi dalam penelitian ini berjumlah 56 remaja putri di Asrama Kebidanan Poltekkes Kemenkes Pontianak. Peneliti mengambil sampel sebanyak 17 responden yang memenuhi kriteria inklusi sebagai subjek penelitian pada periode Mei - Juni 2019.

Cara pemilihan sampel pada penelitian ini menggunakan teknik purposive sampling dengan kriteria inklusi bersedia menjadi responden, remaja berusia 17-24 tahun, tidak punya riwayat alergi terhadap sayuran wortel dan siklus haid teratur. Sedangkan kriteria eksklusi yaitu sedang memiliki penyakit berat seperti penyakit endometriosis, mioma uteri (tumor jinak kandungan), stenosis serviks, dan malposisi uterus serta mengkonsumsi obat anti nyeri yang bersamaan dengan jus wortel. $[12,16]$ Pemberian jus wortel 2 kali sehari dengan selang waktu 4 jam setelah pemberian yang pertama dengan takaran wortel 250 gram dicampur dengan air mineral 200 cc, jus wortel diberikan selama 2 hari atau selama nyeri haid berlangsung. Kemudian hari ketiga melakukan pengukuran skala nyeri lagi untuk melihat hasil perbedaan sebelum dan sesudah diberikan jus wortel selama dua hari.[13]

Data yang digunakan pada penelitian ini adalah data primer dimana data diperoleh langsung dari responden yang menjadi objek dalam penelitian ini kemudian analisis univariat dilakukan dilanjutkan dengan analisis bivariat untuk melihat pengaruh antara variabel bebas dan terikat. Namun, sebelum dilakukan uji antara masing-masing variabel, data terlebih dahulu dilakukan uji normalitas untuk mengetahui apakah data berdistribusi normal atau tidak. Uji normalitas menggunakan uji Shapiro-Wilk. Hasil uji dengan melihat apabila nilai signifikan $>0,05$ maka data berdistribusi normal. $[12,16]$ 
Tabel 1

Distribusi Frekuensi Responden Berdasarkan Karakteristik

\begin{tabular}{clcc}
\hline No & Karakteristik & $\begin{array}{c}\text { Jumlah } \\
(\mathbf{n = 1 7})\end{array}$ & Persentase \\
\hline 1. & Usia & 2 & $12 \%$ \\
& 17 tahun & 15 & $88 \%$ \\
$\quad \begin{array}{l}\text { 17 tahun } \\
\text { 2. }\end{array}$ & 15 arche & 11 & $65 \%$ \\
& $\begin{array}{l}\text { 9-12 tahun } \\
\text { 13-16 tahun }\end{array}$ & 6 & $35 \%$ \\
3. Lama & & \\
& Menstruasi & & \\
& $<7$ hari & 13 & $76 \%$ \\
& $>7$ hari & 4 & $24 \%$ \\
\hline
\end{tabular}

Tabel 2

Skala Nyeri Dismenorea Primer Sebelum dan Sesudah Pemberian Jus Wortel

\begin{tabular}{cccccc}
\hline \multicolumn{3}{c}{ Median Selisih } & $\begin{array}{c}\text { Std. } \\
\text { Deviasi }\end{array}$ & $\begin{array}{c}\mathrm{Mi} \\
\mathrm{n}\end{array}$ & $\begin{array}{c}\mathrm{Ma} \\
\mathrm{x}\end{array}$ \\
\hline $\begin{array}{c}\text { Sebelum } \\
\text { Pemberian }\end{array}$ & 6,00 & 4,00 & 1,437 & 3 & 7 \\
$\begin{array}{c}\text { Jus Wortel } \\
\text { Sesudah }\end{array}$ & & & & & \\
$\begin{array}{c}\text { Pemberian } \\
\text { Jus Wortel }\end{array}$ & 2,00 & & 1,068 & 1 & 5 \\
\hline
\end{tabular}

Tabel 3

Hasil Uji Normalitas Data dan Perbedaan Skala Nyeri

\begin{tabular}{cccc}
\hline & $\begin{array}{c}\text { Normalitas } \\
\text { Data }\end{array}$ & Mean & $p$ \\
\hline $\begin{array}{c}\text { Sebelum } \\
\text { pemberian Jus } \\
\text { Wortel } \\
\begin{array}{c}\text { Sesudah } \\
\text { pemberian Jus } \\
\text { Wortel }\end{array}\end{array}$ & 0,012 & 5,24 & \\
*ket: Uji Shapiro-Wilk dan Wilcoxon & \\
\hline
\end{tabular}

\section{Hasil dan Pembahasan}

Tabel 1. menunjukkan bahwa sebagian besar responden pada penelitian ini berada pada usia > 17 tahun yaitu 17 responden (88\%), Berdasarkan usia menarche sebagian besar pada usia 9-12 tahun yaitu 11 responden (65\%), dan berdasarkan lama menstruasi sebagian besar $<7$ hari yaitu 13 responden $(76 \%)$. Tabel 2 menunjukkan bahwa nilai tengah skala nyeri dismenorea primer sebelum pemberian jus wortel adalah 6,00 dan sesudah pemberian jus wortel menjadi 2,00. Kemudian didapatkan selisih sebelum dan sesudah diberikan jus wortel adalah 4,00. Berdasarkan Std. Deviation sebelum pemberian jus wortel adalah 1,437 dan sesudah pemberian jus wortel menjadi 1,068. Berdasarkan minimum dan maximum sebelum pemberian jus wortel adalah dari 3 sampai 7, sedangkan minimum dan maximum sesudah pemberian jus wortel menjadi 1 sampai 5 .

Tabel 3. menunjukkan uji normalitas data sebelum pemberian jus wortel nilai $p=0,012$ yang menunjukkan bahwa data tidak berdistribusi normal dan data sesudah pemberian jus wortel nilai $p=0,064$ yang menunjukkan data tidak berdistribusi normal. Maka dapat dilanjutkan dengan uji Wilcoxon untuk mengetahui perbedaan skala nyeri sebelum dan sesudah diberikan jus wortel, didapatkan nilai $\mathrm{p}$ value $=0,000(\mathrm{p} \leq 0,05)$ sehingga dapat dinyatakan bahwa ada perbedaan nyeri dismenorea primer pada remaja putri sebelum dan sesudah diberikan jus wortel.

Berdasarkan hasil dari penelitian yang peneliti lakukan di Asrama Kebidanan Poltekkes Kemenkes Pontianak mengenai pemberian jus wortel untuk mengurangi nyeri dismenorea primer pada remaja putri menunjukkan bahwa karakteristik responden penelitian sebagian besar berada pada usia $>17$ tahun yaitu 15 responden (88\%). Pada umur tersebut perkembangan seks sekunder dan hormon tubuh tidak stabil sehingga dapat merangsang hormon prostaglandin yang menyebabkan kontraksi uterus meningkat dan terjadi dismenorea. [10]

Usia menarche sebagian besar pada usia 9 12 tahun yaitu 11 responden (65\%). Penelitian ini sejalan dengan hasil penelitian sebelumnya bahwa usia menarche paling banyak terjadi pada usia 12 tahun yaitu 70 remaja putri $(47,3 \%)$. Usia menarche dapat dipengaruhi oleh beberapa faktor diantaranya berdasarkan penelitian yang lain bahwa yang menjadi faktor usia menarche adalah gaya hidup, nutrisi, gizi, paparan media massa, dan usia menarche ibu (genetik). [18]

Lama menstruasi sebagian besar $<7$ hari yaitu $13(76 \%)$ responden. Penelitian ini berbeda dengan hasil penelitian yang lalu bahwa lama menstruasi yang normal ( $<7$ hari) lebih kecil kemungkinan untuk mengalami dismenorea sebesar 0,19 kali.

Hasil uji statistik dengan Wilcoxon sebelum dan sesudah diberikan jus wortel bahwa nilai $\rho$ value $0,000<0,05$. Sehingga dapat disimpulkan bahwa pemberian jus wortel pada remaja putri dapat mengurangi nyeri dismenorea primer.

Dismenorea adalah nyeri pada saat menstruasi, rasa nyeri ini biasanya dirasakan di 
bagian perut bagian bawah atau pinggang, bisa juga disertai dengan rasa mual, sakit kepala, perasaan mau pingsan dan tanpa disertai adanya tanda-tanda infeksi atau penyakit panggul. Hal ini sesuai dengan tingkat dismenorea yang dirasakan oleh remaja putri di Asrama Kebidanan Poltekkes Kemenkes Pontianak, seseorang yang mengalami dismenorea akan berdampak pada aktivitas yang dilakukan sehari-hari, khususnya pada remaja putri yang mengalami dismenorea. Secara tidak langsung dismenorea akan mengganggu aktivitas pemenuhan kebutuhan sehari-hari seperti perkuliahan dikampus, belajar, bahkan dalam menyelesaikan tugas.[4]

Vitamin E pada wortel dapat mengurangi nyeri pada menstruasi karena Vitamin E mampu membantu pengeblokan formasi prostaglandin dan mengatasi efek peningkatan produksi hormon prostaglandin.[5] Kandungan magnesium pada wortel dapat digunakan untuk kekuatan tulang, mengaktifkan vitamin $\mathrm{B}$, merilekskan otot dan syaraf, pembekuan darah dan produksi energi. Wortel juga mengandung analgetik alami yang berperan seperti obat analgetik (contoh ibuprofen) dan sebagai anti inflamasi.[15]

Penelitian menunjukkan hasil uji statistik dengan Wilcoxon sebelum dan sesudah diberikan jus wortel dengan nilai $\rho$ value $0,000<0,05$ yang berarti ada pengaruh pemberian jus wortel terhadap nyeri dismenorea. Maka dapat dikatakan H0 ditolak atau Ha diterima.[11] Penelitian ini juga sejalan dengan penelitian dengan hasil analisis Wilcoxon Match Paired Test didapatkan Asymp. Sig 0,001 $(p<0,05)$ maka Ha diterima dan Ho di tolak. Hal tersebut menunjukkan bahwa ada pengaruh pemberian air perasan wortel terhadap berbagai tingkat nyeri dismenorea pada mahasiswa dengan $p=0,001$.[14]

Penelitian ini didukung oleh penelitian tentang efektivitas jus wortel (Daucus carota) terhadap penurunan derajat dismenorea pada remaja putri di asrama putri mahasiswa Stikes 'Aisyiyah Yogyakarta, pada kelompok kontrol tidak terjadi banyak penurunan sedangkan pada kelompok eksperimen terjadi banyak penurunan sehingga jus wortel (Daucus Carota) dapat menurunkan derajat dismenorea.[17]

Hasil penelitian sebelumnya tentang pengaruh pemberian jus wortel terhadap penurunan tingkat dismenorea primer pada mahasiswi DIV Bidan Pendidik Semester IV di Universitas Aisyiyah Yogyakarta menyebutkan hasil pretest dan posttest pada kelompok kontrol menunjukkan bahwa setiap responden yang diberikan intervensi berupa pemberian jus wortel mengalami penurunan tingkat dismenorea dengan angka maksimal skala 7 (nyeri berat) menjadi skala 3 (nyeri ringan), dan tingkat dismenorea minimal pada skala 2 (nyeri ringan) menjadi skala 0 (tidak nyeri). Setelah diberikan intervensi terjadi selisih penurunan dengan selisih maksimal 6 dan minimal 2.[13]

\section{Simpulan}

Berdasarkan hasil penelitian yang telah dilakukan mengenai pemberian jus wortel untuk mengurangi nyeri dismenorea primer pada remaja putri di Asrama Kebidanan Poltekkes Kemenkes Pontianak, maka dapat disimpulkan: Nilai tengah nyeri dismenorea primer sebelum pemberian jus wortel di Asrama Kebidanan Poltekkes Kemenkes Pontianak adalah 6,00 dan sesudah pemberian jus wortel adalah 2,00 dengan selisih 4,00. Ada perbedaan nyeri dismenorea primer sebelum dan sesudah pemberian jus wortel pada remaja putri di Asrama Kebidanan Poltekkes Kemenkes Pontianak

\section{Daftar Pustaka}

[1] Agust, W. Pengaruh Minum Kunyit Asan Terhadap Penurunan Tingkat Nyeri Dismenorea pada Siswi di Madrasah Tsanawiyah Negeri Jatinom Klaten (Jurnal). 2014

[2] Agust. Psikologi Remaja Perkembangan Peserta Didik. Edisi Kedua. Jakarta : EGC. 2009.

[3] Devi,N. Gizi Anak Sekolah. Kompas Media Nusantara:Jakarta. 2012.

[4] Farotimi, A. A. Knowledge, Atitude, And Healthcare Seeking Behavior Towards Dysmenorrhea Among Female Students Of A Private University In Ogun State Nigeria. Journal of Basic and Clinical Reproductive Science. Vol 4 issue 1. Http://jbcrs.org. 2015.

[5] Hembing, W. Penyembuhan dengan Wortel. Jakarta: Pustaka Populer Obor. 2007.

[6] Judha, Mohamad dkk. Teori Pengukuran Nyeri dan Nyeri Persalinan. Yogyakarta: Nuha Medika. 2012.

[7] Junizar G, Sulianingsih. Pengobatan Dismenore Secara Akupuntur. 2008.

[8] Kusmiran, Eny. Kesehatan Reproduksi Remaja dan Wanita. Jakarta : Selemba Medika. 2011.

[9] Lestari, Dwi Rafita dan Citrawati,Mila. Hubungan Aktivitas Fisik dan Kualitas Tidur 
dengan Dismenorea pada mahasiswi FK UPN "Veteran" Jakarta. 41.2 (2018): 48-58.

[10] Manurung, Melda Friska, dan H. D. Rahmalia. Efektivitas Yoga Terhadap Nyeri Dismenore Pada Remaja. Diss. Riau University. 2015.

[11] NL, Mega Puspita. Pengaruh Pemberian Jus Wortel Terhadap Nyeri Dismenorea Pada Remaja Putri. (Jurnal). 2018.

[12] Notoadmodjo. Metodologi Penelitian Kesehatan. Jakarta: PT Rineka Cipta. 2012. Novarita, N., \& Kurniati, N. Pengaruh Pemberian Jus Wortel Terhadap Penurunan Tingkat Dismenore Primer Pada Mahasiswi Div Bidan Pendidik Semester Iv Di Universitas Aisyiyah Yogyakarta (Doctoral Dissertation, Universitas' Aisyiyah Yogyakarta). 2017.
[13] Puji,H. Sumiyati, Fajaria,N.A. Pengaruh pemberian air perasan wortel terhadap berbagai tingkat nyeri dismenore pada mahasiswa prodi kebidanan purwokerto. (Jurnal). 2016.

[14] Silvia, D.J.C. Nutritional and Health Benefits of Carrots and Their Seed Extracts. Journal of Food and Nutrition Sciences. 5, 2147-2156. http://dx.doi.org/10.4236/fns. 2014.522227. (Jurnal). 2014.

[15] Sugiyono. Statistika untuk Penelitian. Jakarta: Alfabeta. 2011.

[16] W Handhika, St Wibowo. Efektivitas Jus Wortel (Daucus Carota) Terhadap Penurunan Derajat Dismenorea Pada Remaja Putri Di Asrama Putri Mahasiswa STIKES 'Aisyiyah Yogyakarta. (Jurnal). 2010.

[17] Wulandari, Anisa, Oswati Hasanah, dan Rismadefi Woferst. "Gambaran Kejadian dan Manajemen Dismenore pada Remaja Putri di Kecamatan Lima Puluh Kota Pekanbaru." 2018. 